\title{
SAÚDE MENTAL NOS TEMPOS DE PANDEMIA: UMA RELEITURA DOS AFETOS E DA PULSÃO DE MORTE EM FREUD
}

\section{MENTAL HEALTH IN PANDEMIC: AN REREADING OF AFFECTIONS AND THE DEATH INSTINCT IN FREUD}

Luzia Carmem de Oliveira ${ }^{1}$

\section{RESUMO}

Pretende-se com este artigo refletir sobre possíveis impactos da pandemia de Covid-19 à saúde mental, buscando compreender como as pessoas reagem afetivamente diante de uma situação traumática, tomando como base os conceitos de afeto e pulsão de morte em Freud. A pandemia impõe uma alteração significativa na vida da população em função do risco de adoecimento e consequente morte, obrigando a uma significativa parcela da população a viver em isolamento/ distanciamento social por algum tempo e obriga a todos a uma série de restrições, gerando sofrimento. Este trabalho visa contribuir para a compreensão da vivência subjetiva a partir da trágica situação de pandemia que deixa suas marcas na história da humanidade.

Palavras-chave: Afeto. Pulsão de Morte. Angústia. Pandemia. Saúde Mental.

\section{ABSTRACT}

The aim of this article is to reflect on the possible impacts of the Covid-19 pandemic on mental health, seeking to understand how people react emotionally in the face of a traumatic situation, based on the concepts of affection and death instinct in Freud. The pandemic imposes a significant change in the life of the population due to the risk of illness and consequent death, forcing a significant portion of the population to live in social isolation / distance for some time and forces everyone to a series of restrictions, causing suffering. This work aims to contribute to the understanding of the subjective experience from the tragic pandemic situation that leaves its marks in the history of humanity.

Keywords: Affection. Death Instinct. Anguish. Pandemic. Mental Health.

\footnotetext{
1 Psicanalista, Mestre em Psicologia, especialista em Saúde mental. Sócia Associação Psicanalítica de Curitiba, Curitiba-Pr-Brasil, E-mail: Icarmem@hotmail.com
} 


\section{INTRODUÇÃO}

"E agora José?

A festa acabou, A luz apagou, O povo sumiu, A noite esfriou, e agora José?"

Drummond

Século XXI, ano de 2020 se inicia com as primeiras notícias a respeito de uma gripe gerada pelo vírus que ficou conhecido por novo Corona, por se tratar de um vírus já existente anteriormente, porém no momento em uma nova cepa, que aparece primeiramente na China. A doença gerada pelo novo vírus é nomeada pela Organização Mundial de Saúde (OMS) de Covid $-19^{2}$.

No decorrer de poucos meses, em um mundo que é globalizado para algumas coisas e segregado para outras (vide situação dos imigrantes), o vírus rapidamente também vai se globalizando, não somente pelas notícias do alastramento da doença, mas por sua própria circulação, que produziu um cenário de pandemia (doença amplamente difundida) e com isso mudanças significativas foram impressas na vida da população mundial. Uma situação extremamente preocupante, que envolve a todas as pessoas, em todos os países e continentes, em uma ameaça real imposta pelo vírus.

Pelo seu caráter de rápido contágio e significativo tempo de sobrevivência do vírus em superfícies fora do corpo humano, não há forma infalível de se proteger da contaminação de modo que os cuidados mais efetivos encontram-se no estabelecimento de barreiras físicas de contenção ao vírus. Sendo assim, a orientação mais contumaz da OMS quanto à prevenção é a realização do isolamento/distanciamento social, ou seja, a população deve permanecer mais tempo em suas casas, restringindo sua circulação pela polis e o contato social/físico deve ser evitado. Nas breves situações sociais, como ir ao supermercado, indica-se a utilização de máscaras além da constante higienização das mãos. “E agora José?” Da noite para o dia toda a população mundial se vê diante de uma série de restrições, privada das experiências sociais, dos encontros, do contato físico.

Em “Ensaio sobre a cegueira", celebre livro de autoria de Saramago (1995), o autor faz uma elaboração que remete ao cenário real criado pela pandemia. Em sua obra o mundo é acometido por uma epidemia de cegueira, começando com alguns infectados que são isolados em um manicômio para período de quarentena. O que pode advir do humano quando precisa viver em isolamento e passa a conviver com mais intensidade com outras pessoas? À medida que a convivência avança no tempo, vai se tornando difícil se organizarem neste formato e

2 “que significa Corona Vírus Disease, enquanto 19 se refere ao ano 2019”, Fundação Oswaldo Cruz (Fiocruz) (https://portal.fiocruz.br/ recuperado em 12 de Abril, 2020). 
passam a assumir comportamentos irracionais, instintivos, deixando vir à tona o que há de mais primitivo no humano, assim demonstra o livro.

O romance de Saramago toca em questões como Ética, afeto, solidariedade, em como ser sujeito se relacionando com um grupo e a nova organização da vida gerada pela pandemia e consequentemente o isolamento social, traz questões muito próximas, senão as mesmas que atravessam a todos. Com uma série de situações novas, muitos questionamentos e preocupações com a saúde física, saúde mental, financeira, modo de viver, dentre outras coisas, acomete à população e aos estudiosos.

Quando as primeiras notícias a respeito da situação de contágio e mortes causado pela Covid-19, ocorridas na China, chegam ao Brasil não era incomum brincadeiras a respeito da situação por parte de uns e a indignação, medo ou solidariedade por parte de outros. À medida que a situação avança no Brasil a população vai aderindo ao isolamento, escolas e universidades suspendem as aulas, muitas empresas se organizam para pararem seus serviços, pequenos e microempreendedores se veem obrigados a fecharem seus negócios. O país fica dividido entre aqueles que podem realizar o isolamento social e outros que continuam trabalhando em serviços essenciais.

Com frequência as notícias fazem referência à situação da pandemia como sendo uma guerra, com toda uma linguagem bélica na luta da saúde contra a doença detonada por um vírus, trazendo traços de similaridade com outros momentos históricos da humanidade, onde houveram muito sofrimento, angústia, devastação, como os períodos em que o mundo esteve em guerra ou período da gripe Espanhola, por exemplo. A situação remete-nos ao livro "O Diário de Anne Frank", que relata sua vivência em um esconderijo no período da Segunda Guerra Mundial e auxilia a pensar neste modelo de isolamento social na pandemia, embora nos dias de hoje, ainda haja alguma possibilidade de liberdade, as redes sociais e todos os recursos tecnológicos permitem aproximações com pessoas distantes e notícias do mundo, e a ameaça à vida ocorre de outro modo.

Algo muito particular no caso da contaminação pelo novo corona está no fato de que o maior cuidado com a saúde reside em assumir uma atitude que não permita a propagação do vírus às pessoas próximas fisicamente. Isso significa que cada sujeito deve se proteger e assim estará automaticamente protegendo o outro, implicando a todos em uma cadeia de solidariedade. Mas o que significa ser solidário?

A palavra solidariedade que em nossa cultura por vezes é romantizada e remete a uma atitude de ajuda ao outro, significa dentre outras coisas: qualidade de quem está disposto a ajudar, partilha de interesses, refere-se a uma responsabilidade mútua (Ferreira, 1999). O cenário criado pela pandemia convoca a todos a assumir a solidariedade, onde cuidar de um significa cuidado com os demais, sendo necessário uma atitude ativa do sujeito que também ganha algo e não somente oferece ao outro, ou seja, o sujeito deve se implicar na situação.

No período em que ocorre a primeira guerra mundial, Freud que andava na efervescência de seu trabalho com a Psicanálise, com uma intensa investigação clínica e desenvolvimento da teoria, escreve um texto fazendo considerações sobre a guerra e a morte. Seu testemunho: 
Apanhados no torvelinho desse tempo de guerra, informados de maneira unilateral, sem distanciamento das grande mudanças que já ocorreram ou estão para ocorrer e sem noção do futuro que se configura, ficamos nós mesmos perdidos quanto ao significado das impressões que se abalam sobre nós e quanto ao valor dos julgamentos que formamos...Mas provavelmente sentimos o mal desse tempo com intensidade desmedida, não tendo o direito de compará-lo com aquele de tempos que não vivenciamos (Freud, 1915b, p. 210).

Facilmente conseguimos transpor os sentimentos descritos por Freud para o período da pandemia de covid-19, pois de fato algumas questões ficam muito incertas quanto ao futuro, retomada da vida, quanto tempo levará para que os riscos da pandemia passem, quais os impactos na saúde mental, nos relacionamentos, nos trabalhos, somente para mencionar algumas incertezas. Assim, obrigados a uma nova organização de vida, em isolamento social, as famílias/pessoas passam a incorporar uma realidade nunca vivida anteriormente por esta geração, com uma mudança significativa nas rotinas das casas, gerando questionamentos nos profissionais da área da saúde mental: Como as pessoas reagem afetivamente com essa nova forma de viver a partir da pandemia de convid-19?

Da nova forma de se organizar, de tentar se proteger e proteger às demais pessoas, profissionais tem se debruçado para estudar e trabalhar sobre esse tema e aqui refletimos sobre a saúde mental da população, visto serem muitos os questionamentos. Buscando esclarecimentos acerca da subjetividade, que nos auxilie no trabalho com a saúde mental, em todos os tempos, mas aqui inspirados pelos tempos de pandemia, faremos um percurso a partir da teoria psicanalítica Freudiana, tomando como fio condutor os trabalhos que fazem referências aos afetos e à pulsão de morte.

\section{OS AFETOS}

"Suponho que me entender não é uma questão de inteligência e sim de sentir, de entrar em

contato...

Ou toca, ou não toca."

Clarice Lispector

O sujeito é acometido por afetos e apresenta reações diversas ao vivenciar uma situação traumática até que consiga simbolizar essa nova experiência e para alcançar essa elaboração precisará fazer uma travessia por limites humanos e pela realidade da finitude da vida, pelo desamparo, mesmo que não tenha uma percepção consciente a esse respeito. Ao se confrontar com o risco de falência do corpo reações como negação, minimização ou supervalorização da situação e alterações do humor, podem acometer o sujeito, de modo que o risco de morte é uma vivência difícil de subjetivar, sendo necessário um tempo para a elaboração psíquica, que é uma experiência sempre singular. 
A teoria dos afetos está presente nas pesquisas de Freud desde suas primeiras investigações acerca da neurose, de modo que o tema é contemporâneo ao nascimento da própria psicanálise, apesar de que não houve de sua parte dedicação para delinear uma definição ou sua natureza (do afeto). Ao trabalhar com os sonhos dos seus pacientes, Freud (1900/2019) buscava seguir a trilha dos afetos observando que esses elementos atravessam a produção onírica, que é uma produção cifrada apresentando o conteúdo manifesto, aquele que aparece na superfície e o conteúdo latente, aquele que fica encoberto e necessita ser interpretado para que haja alguma compreensão.

Ainda em seu trabalho com os sonhos Freud (1900/2019) tende a ler os afetos como a forma que a representação chega até o consciente do sujeito e o afeta causando prazer ou desprazer. Deste modo, o afeto possui uma ação qualitativa sendo necessária a participação da consciência e não apresentando nenhuma localização tópica, Winograd e Teixeira (2011).

Tomando uma explicação da Filosofia, Corrêa (2005) destaca que afeto se refere a emoções positivas. Enquanto as emoções fazem referências a pessoas ou coisas, os afetos por sua vez acompanham as relações interpessoais, não havendo um domínio da paixão. Acerca do afeto: “Termo que a Psicanálise foi buscar na terminologia psicológica alemã e que exprime qualquer estado afetivo, penoso ou desagradável, vago ou qualificado, quer se apresente sob a forma de uma descarga maciça, quer como tonalidade geral (Laplanche \& Pontalis, 2001, p. 9). Assim, em Psicanálise o afeto possui relação com a pulsão e ela será responsável em dar o tom qualitativo e quantitativo para as vivências psíquicas do sujeito.

Quando lidar com a realidade se torna difícil ou até insuportável em função de uma situação que gera grande desprazer o Ego do sujeito busca formas de se afastar dela, sendo a neurose uma das saídas possíveis para esse impasse. Vivendo um evento que gera uma alta de tensão o Ego atua no sentido de tentar reprimir essa sensação, negando a realidade apresentada e assim buscando reduzir o desprazer. Deste modo os processos psíquicos são regulados pelo princípio do prazer, mas não significa que sejam dominados por ele, pois se assim o fosse os processos mentais deveriam ser sempre acompanhados por uma sensação prazerosa, mas facilmente observamos que não é isso o que ocorre, Freud (1920/2010).

$\mathrm{O}$ aparelho psíquico lida com o aspecto não somente qualitativo de uma experiência, mas também quantitativo, onde havendo alta cota de estímulos há três diferentes formas que esses afetos podem ser transformados: a conversão nas histerias, o deslocamento nas obsessões e a transformação na angústia e melancolia, como Freud (1950 [1892-1899]) descreve na carta 18 a Fliess .

No ano de 1918, no V Congresso Psicanalítico em Budapeste, foram apresentados alguns trabalhos a respeito das chamadas neuroses de guerra, quadros esses desenvolvidos pelos soldados por ocasião da I Guerra mundial. Freud (1919/2010) observa que finalizada a guerra essas doenças neuróticas desaparecem completamente para algumas pessoas e foram produzidas a partir de um conflito do Ego, sendo que esses quadros diferem das neuroses dos tempos de paz por certas particularidades. As neuroses de guerra são neuroses traumáticas, que ocorrem após uma situação grave, um choque e que não é o resultado de um conflito interno ao Ego, mas de um conflito entre o Ego e o mundo externo. 
Essas neuroses apontam para o que Freud (1926/2014) postulou como desamparo humano ou estado de desamparo (Hilflosigkei em alemão), que é constitutivo da subjetividade, estruturante da vida psíquica. Dentre outras questões, isso passa pelo fato de que o filhote humano tem uma dependência do outro que lhe provê os cuidados, pois sem isso não seria possível sua sobrevivência. Para sobreviver o bebê precisa ser alimentado, hidratado, higienizado, cuidado, investido de libido, de palavras, ele é desamparado primeiro biologicamente e anexo vem o desamparo psíquico. Podemos entrever na instauração do desamparo psíquico o traço que a posteriori na vida será condição para a vivência dos afetos.

Freud (1920/2010) observou que nos quadros de neuroses traumáticas destacam-se duas características: primeiramente as mesmas pareciam causadas pelo fator surpresa do terror e em segundo, um ferimento atuava como protetor contra a neurose, na medida em que o sofrimento aparece no sofrimento do corpo. A observação desses quadros lhe permitiu fazer uma diferenciação entre terror, medo e angústia.

O medo é o afeto despertado diante de determinado objeto, ante o qual o sujeito se amedronta (Freud, 1926/2014) e que possui um caráter protetivo na medida em que auxilia no cuidado para a preservação da vida. Com a pandemia de corona vírus, quando as pessoas sentem medo é possível canalizá-lo para cuidados com a contaminação, de modo a se proteger utilizando as medidas de segurança orientadas pelos serviços de saúde.

Na contemporaneidade o medo é o afeto que se encontra na base dos quadros de fobia e do transtorno do pânico, descritos pela psiquiatria em seu Manual Diagnóstico (DSM-V, 2014), e que geram sérios prejuízos à vida do sujeito. Pode-se apreciar que nestes quadros de transtornos psiquiátricos a incidência do medo se dá em uma medida que leva o sujeito a um nível de sofrimento elevado que resulta em limitações na organização da vida.

Em contrapartida o terror ocorre quando o sujeito é acometido por uma situação de perigo sem estar preparado para ela e assim é tomado de surpresa. No quadro de neurose traumática os sonhos produzidos sempre retornam à situação traumatizante, renovando o terror vivido naquele momento, sendo essa uma descrição aproximada dos quadros conhecidos atualmente como Transtorno de Estresse pós-traumático (TEPT).

Em seu trabalho Inibição, sintoma e angústia (1926/2014), Freud aprofunda e esclarece sua teoria acerca desses afetos. A inibição é um efeito de rebaixamento ou uma restrição em uma função, não sendo algo necessariamente patológico, tratando-se de uma limitação funcional do Ego e que pode ter muitas causas. As inibições podem atingir as funções sexual, de nutrição, locomoção ou trabalho profissional tendo como função a evitação da angústia, ou seja, é uma limitação que ocorre por precaução.

Ao viver uma situação que gera muita tensão o sujeito pode sentir um rebaixamento na libido sexual, falta de vontade de comer ou exatamente o contrário, uma compulsão alimentar, falta de energia para andar ou realizar atividades físicas, dificuldade de concentração no trabalho ou na realização de tarefas corriqueiras, atenção difusa, dentre outras coisas. Não é algo incomum escutar queixas em relação a inibições dessas funções, o que gera uma incompreensão nas pessoas e se tornam queixas com relação à saúde mental. 
Dito de outro modo, quando o Ego do sujeito é convocado a lidar com uma tarefa psíquica que lhe resulta difícil (por exemplo o luto), há uma supressão do afeto que faz com que ele se empobreça no tocante à energia disponível e por isso precisa retirá-la de outros lugares. Freud (1926/2014) chamou esse mecanismo de inibição de curta duração, sendo a inibição essa limitação da função do Ego que buscando se precaver do empobrecimento de energia, reduz o seu dispêndio de outros lugares.

Ao vivenciar o período da pandemia, com a suspensão de atividades sociais e a restrição imposta pelo isolamento social se estabelece um trabalho de luto por tantas mudanças, de modo que o aparelho psíquico precisa se reorganizar no tocante a seu consumo de energia. É frequente o relato de pessoas quanto a sentirem-se perdidas, com uma sensação de confusão temporal e emocional, com uma sobrecarga de difícil descrição, por não ser condizente com as atividades diárias mas que geram grande exaustão.

Diferente da inibição, para Freud (1926/2014) o sintoma indica um processo patológico em curso e o mesmo não se encontra no Ego. Quando o Ego recebe excitações tanto internas quanto externas, as sensações de prazer-desprazer que o acometem, buscam encaminhar o desenvolvimento psíquico para o prazer. O sintoma vai aparecer como o substituto de uma satisfação pulsional que não se deu por conta da repressão, de modo que o Ego garante que a ideia se mantenha fora da consciência e seja conservada como formação inconsciente.

Um dos mecanismos utilizado pelo Ego para lidar com o desprazer diante de um perigo externo ou interno é a fuga, embora ela ocorra de modos diferentes nas duas situações. Diante de um perigo externo o organismo se prepara para fugir, realizando uma série de cálculos e alguns comandos são enviados aos músculos para que haja uma atitude de proteção. Um homem ao se deparar com uma situação de violência pode se preparar para a fuga ante o perigo que essa situação representa, por exemplo.

$\mathrm{O}$ equivalente à fuga que ocorre no mundo externo, no mundo interno ocorre a repressão. "O Eu retira o investimento (pré-consciente) do representante do instinto a ser reprimido e o aplica na liberação do desprazer (angústia)" (Freud, 1926/2014, p. 22). Assim a angústia é reproduzida como um estado afetivo segundo uma memória já existente. A partir do inconsciente os estados afetivos vividos no presente fazem parte dos registros de antigas vivências traumáticas e são despertados por símbolos mnemônicos, sendo o ato do nascimento o primeiro evento de angústia individual que um sujeito vive, no entanto não significando que toda angústia seja uma reprodução desse momento do nascimento.

O perigo do mundo interno ao qual Freud se refere e que virá a constituir o sintoma, é a do impulso pulsional produzido no Id, que apesar de sofrer alguma repressão encontra um substituto que é deslocado, atrofiado, inibido e quando ele é concretizado não gera uma sensação de prazer, mas sim uma coerção. Assim, "o sintoma se compara a um corpo estranho que incessantemente gera estímulos e reações no tecido em que se encrustou” Freud (1926/2014, p. 28).

Dito de outro modo, primeiro o Ego luta contra a pulsão tentando reprimi-la e depois essa luta continua contra o sintoma. Essa dinâmica da função do sintoma auxilia a compreender por que ao produzi-lo o Ego não elimina completamente a tensão, mas a reveste em outra 
forma na tentativa de evitar a angústia, pois o sintoma continua constantemente exigindo satisfação do Ego, que emite o sinal de desprazer em sua própria defesa.

Por outro lado, tentando eliminar a estranheza que o sintoma ocasiona o Ego tenta incorporá-lo em sua organização o que por si mesmo já contribui para gerar o próprio sintoma que vai gradualmente se tornando representante de interesses, se entrelaçando no Ego e se tornando imprescindível para esse. Esse entrelaçamento que vai ocorrendo entre o Ego e o sintoma é uma relação difícil de ser modificada ou rompida, pois atuam do lado das resistências, cumprindo uma função para o aparelho psíquico.

Freud (1926/2014) destaca ainda que a angústia é um medo realista ante um perigo propriamente ameaçador ou considerado real, gerando a repressão do impulso que se torna insuportável, sendo essa a angústia da castração. A teoria da castração em Freud, como vários de seus postulados, se apoia na biologia partindo da diferença anatômica dos sexos, destacando a presença do pênis no menino e ausência do mesmo na menina, de modo que o menino teme a castração de seu órgão sendo uma ameaça paterna, enquanto que na menina a falta do pênis é sentida como um dano sofrido, Freud (1908/2015). No entanto essa não seria uma vivência literal, mas um processo simbólico. A castração funda no sujeito o que Lacan (1962/2005) veio a definir como a falta.

Um bebê ao ser atendido pelo outro materno tem uma exigência da presença dessa figura porque sabe que suas necessidades serão satisfeitas. Quando ocorre de não encontrar a Mãe o nível de tensão vai aumentando, gerada pela frustração de não ser atendido, situação essa diante da qual o bebê é impotente. Nessa vivência eclode o desamparo psíquico do bebê tendo como seu produto a angústia, que faz com que ele busque atenção através do choro.

A angústia aparece como uma reação afetiva à falta do objeto, que neste caso é a mãe e assim a castração tem em seu interior a separação do bebê com um objeto que lhe é muito estimado. Quando o Ego percebe o perigo da castração ele dá o sinal de angústia e através do prazer-desprazer inibe o investimento pulsional.

Na neurose traumática onde houve uma ameaça à vida, o "medo da morte deve ser compreendido como algo análogo ao medo da castração e a situação a que o Ego reage é a de ser abandonado pelo superego protetor - pelas forças do destino - de modo que não há mais segurança contra todos os perigos" (Freud, 1926/2014, p. 70). No medo da morte por uma situação real a angústia não apenas é sinalizada como afeto, mas é produzida como algo novo nas condições econômicas da situação. Então a angústia é também uma reação à perda, a uma separação.

Os sintomas são produzidos para retirar o Ego de uma situação de perigo, de modo que a angústia preludia a formação do sintoma ao mesmo tempo em que o sintoma contém a situação de perigo. Esse mecanismo pode ocorrer ao longo da vida do sujeito, não tendo relação com sua idade cronológica, de modo que o adulto não se encontra protegido do retorno da situação angustiosa original. Todo o desenvolvimento Freudiano a respeito da angústia a coloca em um lugar central na constituição do aparelho psíquico, na constituição de um sujeito e o leva a concluir que o Ego é a sede da angústia. 
Lustoza (2015) destaca o comentário de Lacan em 1962 para que não tomemos apressadamente a explicação da angústia quanto uma reação à ausência do objeto, para que não se confunda angústia e desejo. Para ele o único afeto que não mente é a angústia, que se dá na relação de estranhamento com o outro. Os demais afetos são qualificações da libido e não possuem o mesmo status que a angústia. A respeito da falta, Lacan destaca que a angústia surge diante da pretensa completude do outro, diante do risco de que não haja falta no outro.

Dirá Lacan:

O que provoca a angústia é tudo aquilo que nos anuncia, que nos permite entrever que voltaremos ao colo. Não é, ao contrário do que se diz, o ritmo nem a alternância da presença-ausência da mãe.... A possibilidade da ausência, eis a segurança da presença. (Lacan, 1962/2005, p. 64).

Assim, Lacan vai um pouco além das postulações de Freud a respeito da angústia, mostrando que a angústia de separação do bebê em relação à Mãe não se esgota em si mesma, visto que a não separação é que se trata da real ameaça. A separação que funda a falta permite a alteridade e essa é condição essencial para a construção de laço com o outro, visto ser necessário que haja uma diferença.

\section{PULSÃO DE MORTE}

“... que a importância de uma coisa não se mede com fita métrica nem com balanças nem com barômetros etc.

Que a importância de uma coisa há que ser medida pelo encantamento que a coisa produza em nós." Manoel de Barros

Estudiosos defendem que após um período crítico/traumático vivido pela humanidade, como no caso das grandes guerras ou pandemias, as pessoas voltam ao seu estado emocional anterior à situação, enquanto outros estudiosos afirmam que eventos dessa magnitude ocasionam mudanças. Pensamos que é possível vislumbrar algumas mudanças se partirmos do pressuposto que toda experiência vivida imprime algo diferente na subjetividade e buscaremos na teoria das pulsões de Freud alguma luz sobre possíveis mudanças para o humano.

As primeiras postulações de Freud acerca das pulsões aparecem em Os três ensaios sobre a teoria da sexualidade de 1905, mas somente em 1915 ele dedica-se a escrever um trabalho que verse especificamente sobre o tema, Os instintos e suas vicissitudes, justamente no período em que desenvolve seus escritos sobre a Metapsicologia. As pulsões têm como definição algo que se encontra entre o psíquico e o somático, pertence aos dois campos, mas não inteiramente a nenhum deles, tratando-se de um terceiro elemento.

A pulsão caracteristicamente possui uma fonte, uma meta, um objeto e um impulso. A fonte encontra-se em algum órgão do corpo, portanto é algo do campo somático; o impulso é 
a força ou parte motora; a meta da pulsão é sempre a satisfação, que pode se dá por diversos caminhos de modo que é possível haver metas intermediárias ou próximas e a satisfação ser parcial; quanto ao objeto é aquele com o qual a pulsão alcança sua meta, pode ser variável, mudar frequentemente, bem como um mesmo objeto satisfazer várias pulsões, Freud (1915a/2010).

A teoria das pulsões em Freud foi marcada por um dualismo, havendo em um primeiro momento, o dualismo pulsional que opunha pulsões sexuais voltadas para a manutenção da espécie e pulsões do Ego voltadas para a conservação do indivíduo. Em um segundo momento encontra-se o dualismo pulsão de vida e pulsão de morte, sendo o trabalho Além do princípio do prazer publicado em 1920 aquele que introduz as novas ideias nas quais Freud já vinha trabalhando, principalmente após a Primeira Guerra mundial e desenvolve um dos seus conceitos que gera muitas discussões, questionamentos e até controvérsias, pulsão de morte.

Freud (1920/2010) toma como ponto de partida a regulação que os processos psíquicos sofrem pelo princípio do prazer, relacionando prazer e desprazer de forma quantitativa, de modo que o desprazer corresponde a um aumento de excitação e prazer uma diminuição em sua quantidade, isso vivenciado dentro de um determinado período de tempo. Esse mecanismo ocorre com o objetivo de que o aparelho psíquico possa conservar o mais baixo possível ou pelo menos constante a quantidade de excitação presente nele e qualquer coisa que fuja a isso é percebido como desprazer.

O homem é um ser que está constantemente buscando satisfação e Freud o demonstrou através de diversos mecanismos como os sonhos, atos falhos, neuroses. Na dinâmica de funcionamento dos processos psíquicos há na psique uma forte tendência ao princípio do prazer, não significando que ele detenha o domínio, pois se assim o fosse haveria pouca ou nenhuma percepção de desprazer, de modo que não é desta forma que o mecanismo ocorre. Isso suscita questionamentos: o que ocorre então que o princípio do prazer não assume $o$ domínio? O que há de novo neste processo?

Uma primeira inibição para o princípio do prazer é imposta pela ação do princípio de realidade, que não desiste do objetivo de encontrar prazer, mas consegue um adiamento dessa meta e aceita o desprazer temporariamente. Esse processo é responsável apenas por uma pequena parte do desprazer que pode assolar o aparelho psíquico, sendo outra cota proveniente dos conflitos e cisões dentro do próprio aparelho, Freud (1920/2010). Assim, o sujeito está sempre dividido entre o desejo de prazer e as impossibilidades impostas pela realidade ou pelo que se internaliza dela.

Um exemplo da pandemia que nos permite a observação da atuação do princípio do prazer seria a dificuldade que muitas pessoas apresentam em assimilar a orientação para $o$ isolamento social. É comum que com uma mudança, que pode ser extrema na vida, algumas pessoas ainda insistam em manter atividades que são proibidas no momento, como: reuniões sociais, sair às ruas sem máscaras, dentre outras, de modo a não renunciarem àquilo que the geram prazer, negando a realidade. Para outros, no entanto o posicionamento é exatamente o oposto, pensando em adiar o prazer de várias atividades em função de manter a segurança da saúde, buscando uma prevalência da realidade. 
No trabalho terapêutico psicanalítico partindo do funcionamento do Inconsciente, Freud faz um percurso que começa na ideia de que os conteúdos inconscientes deveriam ser desvendados, reunidos e comunicados ao paciente, ou seja, o analista deve fazer uma interpretação desses conteúdos. Constatando que esse mecanismo não concluía a terapêutica um novo mecanismo é introduzido, o paciente é estimulado a fazer sua construção a partir de sua própria lembrança, sendo influenciado a abandonar as resistências através da transferência, que é a maior das resistências, mas fator essencial para que um trabalho de análise seja possível, Freud (1912/2012).

No entanto Freud constata que mesmo com a instalação da transferência e o paciente em associação livre, também não é possível traduzir todos os conteúdos inconscientes em conscientes, algo continua cifrado, de modo que conteúdos que continuam reprimidos passam a ser repetidos como uma vivência atual. As resistências empreendidas pelo paciente não são próprias do inconsciente, visto que o mesmo não as atua, ou seja, a oposição não se dá entre consciente e inconsciente, mas entre o Ego e o reprimido. Sendo assim a compulsão à repetição deve ser atribuída a esse reprimido inconsciente que faz pressão para retornar, Freud (1920/2010).

Buscando compreender a relação entre princípio do prazer e compulsão à repetição Freud (1920/2010) constata que a repetição traz de volta ao presente experiências do passado, mas esse mecanismo não permite alcançar o prazer e essas experiências também não foram satisfações em outros momentos. A compulsão a repetição caracteriza-se como sendo algo 'demoníaco', no sentido de um poder superior, algo que possuí seu próprio funcionamento, de modo que a faz se sobrepor ao princípio do prazer.

A investigação acerca da compulsão à repetição permite a Freud um avanço para o novo dualismo pulsional ao constatar que a pulsão além de ter um caráter que impele à mudança, ao desenvolvimento, ao progresso também possui um caráter que tende à restauração de um estado anterior, ao estado inanimado, pulsões conservadoras que obrigam à repetição. "O objetivo de toda vida é a morte" (Freud, 1920/2010, p.204) e isso pode ser constatado pelo campo biológico, sendo a morte o destino de todo ser vivo, no entanto isso não é suficiente para explicar a natureza dessa oposição ao qual o sujeito está submetido subjetivamente, vida $\mathrm{x}$ morte. $\mathrm{O}$ que está para além do biológico?

Freud assume um outro tom ao destacar que se pode crer que há no ser humano um impulso para a perfeição, para o desenvolvimento que permitiu um alto nível de intelectualidade, sublimação Ética que poderia resultar em um super-homem. No entanto, isso seria uma ilusão, pois para que a busca por essa perfeição seja possível será necessário que uma cota de determinadas pulsões sejam reprimidas, sendo que sempre farão uma pressão na busca pela satisfação, ou seja, há um outro elemento pulsional que se opõe, que resiste ao desenvolvimento do homem.

A primeira concepção dualista que opunha pulsões do Ego a pulsões sexuais é abandonada, passando para o segundo momento com a presença da pulsão de vida e pulsão de morte. Essa visão está em acordo com a constatação de que o princípio do prazer se encontra a serviço da pulsão de morte, pois enquanto as pulsões de vida perturbam a paz interna, 
geram excitações, tensões, trazendo satisfação quando são eliminadas a pulsão de morte faz o seu trabalho silencioso, buscando manter sempre baixa a excitação.

Essa busca em manter uma excitação baixa e constante do aparelho psíquico, foi introduzida por Freud em seu Projeto (1900/1996), onde embasando-se em uma fórmula neurológica ele fala a respeito do princípio de inércia e de constância, dizendo da existência de um quantum que circula e coloca em movimento o aparelho e o faz buscar uma redução e controle desse mecanismo. Essas foram as bases para o desenvolvimento posterior acerca da pulsão de morte.

A dinâmica do princípio do prazer em relação à quantidade de excitação não será o único elemento em funcionamento, pois ocorrerá a regulação também do aspecto qualitativo, de modo que haverá tensões que são prazerosas e distensões que são desprazerosas. Freud (1924/2012) estabelece uma cadeia de relações entre os princípios de modo que eles não se excluem ou se anulam e apresentam o aspecto quantitativo e qualitativo da excitação: "o princípio do Nirvana exprime uma tendência do instinto de morte, o princípio do prazer representa a reivindicação da libido, e a modificação dele, o princípio da realidade, a influência do mundo externo" (p. 187).

A presença do que parece ser a oposição entre vida e morte, pulsão de vida e pulsão de morte, desenvolvimento e destrutividade, progresso e retrocesso é algo revolucionário na teoria Freudiana, estando presente na subjetividade humana e tendo seu desdobramento no meio social, por ser o homem um ser de relação que reproduz no seu meio o que se encontra em seu íntimo. No entanto isso tira o sujeito definitivamente do lugar de bondade ou pureza e coloca-o também como portador de um aspecto destrutivo, ou seja, o homem não é um ser tranquilo, cheio de amor, calmo, ele porta em si uma parte de ódio e uma forte tendência à agressividade (Freud, 1930/2011).

Das concepções Freudianas acerca das pulsões de vida e de morte, pode-se depreender que é necessário que haja um esforço das primeiras no sentido de manter a vida, pois caso isso não ocorre a vida logo sucumbiria à morte. A pulsão de morte de alguma forma atua no sentido de fazer um circuito com a pulsão de vida, havendo um complemento entre uma e outra ou como destaca Freud (1924/2012) ocorre entre as duas pulsões uma mescla, um amálgama, uma mistura de proporções variáveis. Administrando a pulsão de morte de modo que ela não permanece inteiramente no aparelho psíquico, este atua encaminhando para o mundo externo parte da destrutividade, fazendo do homem também um ser de destruição.

Mesmo que uma parte da pulsão de morte seja enviada ao mundo externo uma quantidade da mesma permanece no Ego e pode encontrar saídas construtivas, criativas quando fusionada com a pulsão de vida. Ficando a pulsão de morte desfusionada acaba produzindo neuroses graves e encontra no Superego um aliado, que se responsabiliza pela dureza e rigidez na busca em castigar o Ego, além de lhe impor o sentimento de culpa, Freud (1923/2012).

Buscando compreender melhor essa dinâmica tomaremos o modelo do masoquismo, como explicado por Freud (1924/2012) que se apresenta de três formas na subjetividade e em todas elas tem como base o prazer na dor: erógeno, feminino e moral. O masoquismo 
feminino pode ser observado na manifestação do desejo do sujeito em ser tratado como uma criança desamparada, dependente e malcomportada colocando no jogo sexual a fantasia de ser amordaçado, amarrado, humilhado. Essas manifestações apontam para a vida infantil. Freud chamou esse modelo de masoquismo feminino atribuindo essa posição de ser tratado como criança características femininas, que remetem à castração. Essa fantasia masoquista é também a expressão do sentimento de culpa, pois o sujeito supõe ter infringido algo, por isso deve pagar com castigos penosos.

A libido encontrará pelo caminho a pulsão de morte que busca levar o organismo ao estado inorgânico, a morte. Ela precisa lutar para tornar a pulsão de morte inativa e consegue desviando uma parte da mesma para o mundo exterior, chamando-se pulsão de destruição, apoderamento, vontade de poder, como mencionado anteriormente (Freud, 1924/2012). No entanto uma parte dessa pulsão é colocada a serviço da função sexual, o sadismo, enquanto outra parte permanece no aparelho psíquico com a ajuda da excitação sexual, se liga libidinalmente e então vemos o masoquismo original.

Ocorre entre a pulsão de vida e pulsão de morte uma mescla em proporções variáveis, assim quando uma parte dessa pulsão é colocada para fora, para os objetos, fica no interior o masoquismo erógeno, que por um lado tornou-se componente da libido e por outro tem seu próprio ser como objeto. É possível que sob determinadas circunstâncias, o sadismo ou a pulsão de destruição voltada para fora pode ser novamente internalizado dando origem ao masoquismo secundário (Freud, 1924/2012).

No caso do masoquismo moral a questão está no sofrimento em si, não importando de onde vem, pois o sujeito está sempre disponível para ele. "A pulsão de destruição se volta para dentro e se enfurece com a própria pessoa". O sentimento de culpa inconsciente dificulta a saída de uma neurose, pois o sofrimento que a acompanha é uma valiosa tendência masoquista, sendo que a mesma pode desaparecer quando o sujeito encontra alguma forma de se punir como sugeriu Freud e é possível checar na clínica: "mantendo-se em um casamento infeliz, perder seu patrimônio ou alguma doença orgânica", de modo que o que importa é conservar alguma forma de sofrimento (Freud, 1924/2012, p. 194).

O retorno do sadismo contra a própria pessoa ocorre a partir da repressão cultural que impede que as pulsões destrutivas se apliquem na vida, fazendo surgir no Ego uma intensificação do masoquismo, de modo que o sadismo do Superego e o masoquismo do Ego se completam para produzir as mesmas consequências. Deste modo o sentimento de culpa e a severidade da consciência são mais intensas quando o sujeito se abstém da agressão aos outros.

A parte da pulsão de morte que é enviada para o mundo exterior em forma de agressividade faz com que o homem destrua suas próprias construções, faça do outro semelhante seu escravo, impondo uma série de desigualdades. Isso significa que no social o outro passa a ser visto como um colaborador ou um objeto sexual que pode ser explorado (Freud, 1930/2011), mas internamente isso pode ser um alívio para o sujeito, ao descarregar sua destrutividade no outro. 
O que levou Freud a concluir:

o masoquismo moral vem a ser testemunha clássica da existência da mistura de instintos. Seu caráter perigoso se deve ao fato de proceder do instinto de morte, correspondendo à parte deste que escapou de ser voltada para fora como instinto de destruição. Por outro lado, tendo ele a significação de um componente erótico, também a autodestruição do indivíduo não pode ocorrer sem satisfação libidinal (Freud, 1924/2012, p. 202).

Pulsão de vida e pulsão de morte encontram-se dinamicamente presente no aparelho psíquico, onde ocorrem mesclas em diversas proporções, amálgama entre as duas, fazendo do sujeito um potencial trabalhador em favor do progresso, do desenvolvimento, mas também com seu potencial de destruição. Ao falar em mescla entre pulsão de vida e pulsão de morte Freud (1920/2010) postula a existência no psiquismo de apenas uma pulsão, a de morte, com algumas ramificações e desvios, a pulsão de vida.

\section{CONCLUSÃO}

A pandemia de Covid-19 obrigou às pessoas a mudarem radicalmente suas vidas, assumindo uma série de restrições, se privando de muitas experiências sociais com o objetivo de se precaver de contaminação, adoecimento e morte. Essa situação tem obrigado a população a elaborar formas de se adaptar, enquanto cientistas buscam soluções nos mais variados campos e todos precisam fazer isso enquanto a situação encontra-se em andamento, o número de contaminados e de mortos cresce de maneira exponencial. “E gora José?”.

A novidade e a dimensão da situação despertam nas pessoas um misto de afetos, e mesmo que cada um reaja de forma singular, é possível inferir alguns pontos. Freud nos legou todo um arsenal teórico que nos auxilia a realizar uma leitura da subjetividade, o que nos permite e nos coloca a um trabalho intenso. Destacam-se três afetos principais: o medo que possui um objeto definido e neste caso temos o vírus, um ser micro, invisível aos olhos, com alta capacidade de contágio; o terror despertado com a surpresa da situação, pois tudo aconteceu muito rápido não dando tempo para poder olhar a situação e analisá-la, diretamente foi necessário dar início às elaborações à medida que a situação avança, imersos nela; o terceiro afeto é a angústia.

A angústia tem um lugar diferenciado na subjetividade por estar na base da constituição do sujeito, instaurada a partir da relação primordial com o outro materno, caracteriza-se por ser uma reação diante de um perigo considerado realista. No período de pandemia a angústia despertada pela castração eclode com o que se passa, trazendo à tona em cada sujeito a sua própria falta, seu arranjo subjetivo e a forma como cada um tem que se haver com a castração. Esses elementos fazem com que algo universal, à qual todos estão submetidos toque a cada sujeito de forma singular, encontrando no desamparo o traço primário dos afetos, de modo que nos permite pensá-lo como o afeto base na estruturação do sujeito e que negar a sua existência não o faz desaparecer, o mesmo está inscrito na subjetividade. 
As pulsões também são formas de falar dos afetos em Psicanálise. A pulsão de morte, conceito controverso e ao mesmo tempo revolucionário na teoria freudiana marca que o sujeito não é um ser somente de bondade, mas alguém com potencial para a destruição. Isso coloca dificuldades para a sustentação de um posicionamento solidário, para suportar sustentar $o$ isolamento social, ou ainda para administrar a convivência intensa entre as pessoas dentro de suas próprias casas. A eclosão dos afetos em nível quantitativo elevado e a presença da pulsão de morte, que farão arranjos únicos para cada sujeito, resulta em percepções e reações diferentes e sempre singulares diante da mesma situação.

Podemos vislumbrar que a vivência dos afetos citados anteriormente, principalmente a atualização do desamparo e a eclosão da angústia, pode resultar em um nível de sofrimento elevado para o sujeito, gerando impactos à saúde mental. Na psicanálise Freudiana não encontramos referência ao termo saúde mental tão amplamente utilizado na contemporaneidade, mas fazemos uma aproximação com a subjetividade. Por conta da limitação deste trabalho não pretendemos esgotar as possibilidades de compreensão dos afetos, principalmente da angústia que se mostrou de extrema relevância, nem tampouco da pulsão de morte, que possui sua extensão e nos traz várias possibilidades de articulação.

Concluímos com a compreensão de que a Pandemia impõe uma vivência complexa para a subjetividade, despertando sofrimento, trazendo à tona afetos que assustam e assim fazem com que cada sujeito se confronte com suas próprias questões de forma mais direta, e mesmo sabendo que tudo vai passar, essa passagem possui uma temporalidade e não se sabe qual seria.

Entretanto há também no homem o potencial para o desenvolvimento, para construção e elaborações, contando com os desvios e as ramificações da pulsão de morte em pulsões de vida. As pulsões de vida lutam pela vivência, excitam, incomodam, mobilizam, se fazendo necessário uma atitude ativa do sujeito, investindo em possibilidades para sua articulação.

Em um momento tão crítico, o recurso da palavra, os trabalhos de análises, de terapias, se mostram como uma alternativa essencial para auxiliar na construção de narrativas. Isso permite ao sujeito uma travessia rumo a alguma elaboração simbólica possível, à despressurização da angústia, à elaboração criativa da pulsão de morte, à manutenção de laços sociais e a construção de sonhos que coloquem o futuro em perspectiva.

É importante acreditar que há futuro!

\section{REFERÊNCIAS}

American Psychiatric Association. (2014). Manual diagnóstico e estatístico de transtornos mentais - DSM-5. (M. I. C. Nascimento, Trad.). Porto Alegre: Artes Médicas.

Andrade, C. D. de. (1942). Poesias. Rio de Janeiro: J. Olympio.

Barros, M. (2006). Memórias Inventadas: a Segunda Infância. São Paulo: Planeta.

Corrêa, C. P. (2005). O Afeto no tempo. Estudos de Psicanálise, (28), 61-67. 
Ferreira, A. B. de H. (1999). Novo Aurélio Século XXI: O dicionário de língua portuguesa. (3a ed. rev. e aum.). Rio de Janeiro: Nova Fronteira.

Frank, A. (2000). O diário de Anne Frank (ed. integral). Rio de Janeiro: Record.

Freud, S. (1990). Carta 18. In S. Freud, Publicações Pré-Psicanalíticas e Esboços Inéditos (1950 [1886-1889]) (Ed. Standard Brasileira das Obras Psicológicas Completas de Sigmund Freud, Vol. 1, pp. 100-234). Rio de Janeiro: Imago.

Freud, S. (1996). Um projeto para uma psicologia científica (1950[1895]). In S. Freud. Obras Completas: Publicações Pré-Psicanalíticas e Esboços Inéditos (Vol. 1, pp. 395-506). Rio de Janeiro: Imago.

Freud, S. (2015). Sobre as teorias sexuais infantis (1908). In. S. Freud, Obras Completas: O delírio e os sonhos na Gradiva: Análise da fobia de um garoto de cinco anos e outros textos (1906-1909) (Vol. 8, pp. 390-411). (P. C. de Souza, Trad.). São Paulo: Companhia das Letras.

Freud, S. (2016). Três ensaios sobre a teoria da sexualidade (1905). In S. Freud, Obras Completas: Três ensaios sobre a teoria da sexualidade, análise fragmentária de uma histeria ("O Caso Dora”) e outros textos (1901-1905) (Vol. 6, pp. 13-172). (P. C. de Souza, Trad.). São Paulo: Companhia das Letras.

Freud, S. (2010). Os instintos e seus destinos (1915a). In. S. Freud, Obras Completas: Introdução ao Narcisismo, Ensaios de Metapsicologia e Outros Textos (1914-1916) (Vol. 12, pp. 51-81). (P. C. de Souza, Trad.). São Paulo: Companhia das Letras.

Freud, S. (2010). Considerações atuais sobre a guerra e a morte (1915b). In: S. Freud, Obras completas: Introdução ao Narcisismo, Ensaios de Metapsicologia e Outros Textos (19141916) (Vol. 12, pp. 209-246). (P. C. de Souza, Trad. e notas). São Paulo: Companhia das Letras.

Freud, S. (2010). Introdução a Psicanálise das neuroses de guerra (1919). In. S. Freud, Obras Completas: história de uma neurose infantil ("o homem dos lobos"), além do princípio do prazer e outros textos (1917-1920) (Vol. 14, pp. 382-388). (P. C. de Souza, Trad.). São Paulo: Companhia das Letras.

Freud, S. (2010). Além do princípio de prazer (1920). In S. Freud, Obras Completas: história de uma neurose infantil ("o homem dos lobos"), além do princípio do prazer e outros textos (1917-1920) (Vol. 14, pp. 161-239). (P. C. de Souza, Trad.). São Paulo: Companhia das Letras.

Freud, S. (2011) O mal-estar na civilização (1930). In S. Freud, Obras Completas: O mal-estar na civilização, novas conferências introdutórias à psicanálise e outros textos (1930-1936) (Vol. 18, pp. 13-122). (P. C. de Souza, Trad.). São Paulo: Companhia das Letras.

Freud, S. (2012). A dinâmica da Transferência (1912). In. S. Freud, Obras Completas: Observações Psicanalíticas sobre um Caso de Paranoia Relatado em Autobiografia ("O Caso Schreber”), Artigos sobre Técnica e Outros Textos (1911-1913) (Vol. 10, pp. 133146). (P. C. de Souza, Trad.). São Paulo: Companhia das Letras.

Freud, S. (2012). O eu e o id (1923). In S. Freud, Obras Completas: o eu e o id, "autobiogradia e outros textos (1923-1925) (Vol. 16, pp. 13-74). (P. C. de Souza, Trad.). São Paulo: Companhia das Letras. 
Freud, S. (2012). O problema econômico do masoquismo (1924). In S. Freud, Obras Completas: o eu e o id, "autobiogradia e outros textos (1923-1925) (Vol. 16, pp. 184-202). (P. C. de Souza, Trad.). São Paulo: Companhia das Letras.

Freud, S. (2014). Inibição, sintoma e angústia (1926). In S. Freud, Obras Completas: inibição, sintoma e angústia, o futuro de uma ilusão e outros textos (1926-1929) (Vol. 17, pp.13123). (P. C. de Souza, Trad.). São Paulo: Companhia das Letras.

Freud, S. (2019). A interpretação dos sonhos (I) (1900). (Vol. 4, Ed. Standart Brasileira das Obras Psicológicas Completas de Sigmund Freud). (P. C. de Souza, Trad.). São Paulo: Companhia das Letras.

Lacan, J. (2005). O seminário, livro 10: a angústia. Rio de Janeiro: J. Zahar. (Originalmente publicado em 1962).

Laplanche, J., \& Pontalis, J. B. (2001). Vocabulário da psicanálise (4a ed.). (D. Lagache, Dir.; P. Tamen, Trad.). São Paulo: Martins Fontes.

Lustoza, R. Z. (2015). A Natureza Secreta do Estranho: uma Interpretação Lacaniana da Angústia em Freud. Psicologia: Ciência e Profissão, 35(2), 473-487.

Saramago, J. (1995). Ensaio sobre a cegueira. São Paulo: Companhia das Letras.

Winograd, M., \& Teixeira, L. C. (2011). Afeto e adoecimento do corpo: considerações psicanalíticas. Ágora: Estudos em Teoria Psicanalítica, 14(2), 165-182.

Lispector, C. (1977, fevereiro, 01). Panorama com Clarice Lispector. Recuperado de https:// www.youtube.com/watch?v=ohHP1/2EVnU

Recebido em: 04-05-2020

Primeira decisão editorial: 22-05-2020

Aceito em: 04-06-2020 